Canadian

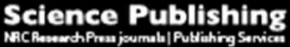

Canadian Journal of Zoology Revue canadienne de zoologie

\title{
Amphibian breeding phenology and reproductive outcome: An examination using terrestrial and aquatic sampling
}

\begin{tabular}{|r|l|}
\hline Journal: & Canadian Journal of Zoology \\
\hline Manuscript ID & cjz-2016-0280.R2 \\
\hline Manuscript Type: & Article \\
\hline Complete List of Authors: & $\begin{array}{l}\text { Greenberg, Cathryn; USDA Forest Service Southern Research Station, } \\
\text { USDA Forest Service } \\
\text { Johnson, Steven; University of Florida, Department of Wildlife Ecology and } \\
\text { Conservatin } \\
\text { Owen, Richard; Department of Environmental Protection, Division of } \\
\text { Recreation and Parks } \\
\text { Storfer, Andrew; Washington State University, School of Biological } \\
\text { Sciences }\end{array}$ \\
\hline Keyword: & $\begin{array}{l}\text { Anuran reproduction, Aquatic sampling, Larval amphibian richness, } \\
\text { Amphibian reproductive outcome, Terrestrial sampling, Tadpole sampling, } \\
\text { Tadpole phenology }\end{array}$ \\
\hline & \\
\hline
\end{tabular}




\title{
Amphibian breeding phenology and reproductive outcome: An examination using terrestrial and aquatic sampling
}

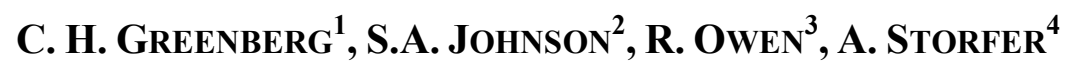

1 Corresponding author: USDA Forest Service, Southern Research Station, Bent Creek

Experimental Forest, 1577 Brevard Rd., Asheville, North Carolina, USA (fax: 828-667-9097;

email: kgreenberg@,fs.fed.us)

2 Department of Wildlife Ecology and Conservation, 110 Newins Ziegler Hall, University of Florida, Gainesville, Florida, USA (email: tadpole@ufl.edu)

3 Florida Park Service, Department of Environmental Protection, 4801 Camp Ranch Road, Gainesville, Florida, USA (email: Richard.Owen@dep.state.fl.us)

4 School of Biological Sciences, Washington State University, Pullman, Washington, USA (email: astorfer@wsu.edu) 


\title{
Amphibian breeding phenology and reproductive outcome: An
}

\section{examination using terrestrial and aquatic sampling}

-C.H. Greenberg, S.A. Johnson, R. Owen, A. Storfer

\begin{abstract}
Worldwide amphibian declines highlights the need for monitoring programs that species presence and track population trends. We sampled larval amphibians with a box trap at 3-week intervals for 23 months in 8 wetlands, and concurrently trapped adults and juveniles with drift fences, to examine spatio-temporal patterns of tadpole occurrence; explore relationships between breeding effort, tadpole abundance, and recruitment, and; compare the efficacy of both methods in detecting species presence and reproductive outcome. Intermittent detection of species within and among wetlands suggested high mortality, followed by deposition of new eggs and tadpole cohorts. Breeding effort, tadpole abundance, and juvenile recruitment were generally not correlated. The reasons for this may include differential bias in detecting species or life stages between methods and high incidence of egg or tadpole mortality. Drift fences detected more species than box traps, but each provided insights regarding amphibian presence and recruitment. Our results illustrate shortfalls in the ability of infrequent aquatic sampling to detect local species richness of larval amphibians, as occurrence of many species is spatially and temporally variable. We also show the importance of using different sampling methods to detect species' presence, and difficulties associated with both methods in tracking breeding effort, tadpole occurrence, or reproductive outcome.
\end{abstract}

Keywords: Anuran reproduction; Aquatic sampling; Larval amphibian richness; Reproductive outcome; Terrestrial sampling; Tadpole sampling; Tadpole phenology 


\section{Introduction}

Many amphibian species breed solely or opportunistically in ephemeral wetlands because they are generally fish-free, with low relative densities of predatory aquatic macroinvertebrates than in more permanent water bodies (Pearman 1995; Skelly 1997). Nonetheless, reproductive success is uncertain in ephemeral habitats, partially owing to variable duration, frequency, timing, and depth of water; wetland drying before metamorphosis results in larval mortality (Greenberg et al. 2015). However, the timing of wetland drying affects species differently due to differences in breeding seasons and rates of larval developmental. Variable hydroregime characteristics within and among wetlands make it unlikely that suitable conditions for successful breeding and recruitment for all species will be consistently available (Snodgrass et al. 2000). Wetland hydrology is strongly affected by the amount and timing of precipitation, making them - and the amphibian populations they support - especially sensitive to altered weather patterns resulting from climate change (Greenberg et al. 2014, 2015).

Concern over amphibian population decline, and vulnerability to climate change, disease, and other environmental threats highlights the need for effective biological monitoring programs (Collins and Storfer 2003). Both long-term terrestrial sampling of amphibians near wetlands, and aquatic sampling of larvae indicate high inter-annual variability in detection, breeding effort, and recruitment (Semlitsch et al. 1996; Trenham et al. 2003; Werner et al. 2007a,b). Terrestrial and aquatic sampling methods are complementary; terrestrial sampling does not explain dynamics of larval abundance or mortality, and aquatic sampling may not reflect breeding effort if egg or tadpole mortality rates are high. Neither method detects all species, and each elucidates only a component of reproduction dynamics. Yet, we are unaware of any study using both 
terrestrial and aquatic sampling methods to examine temporal and spatial dynamics of amphibian breeding through recruitment and, ultimately, long-term population health.

Effective amphibian population monitoring programs must incorporate a combination of methods with sampling frequency, timing, and spatial scale that, together, optimize the likelihood of detecting target species, while minimizing errors in demographic inference (Miller et al. 2011). For example, a species may be temporarily absent or undetected from any given wetland, year, or sampling period due to unsuitable weather or wetland conditions, narrow breeding seasons, rapid larval development rates that affect duration of larval presence, or infrequent or unpredictable breeding behavior (Skelly et al. 2003). Underwater dynamics of competition and predation that vary spatially and temporally can also influence larval presence and reproductive outcome (Wilbur 1982; Morin 1983). Thus, an effective sampling regime requires a basic understanding of the suite of species expected, their life history traits, wetland conditions required for breeding, and a combination of methods that together can detect each species as adults, larvae, and ideally juvenile recruits.

We compared an aquatic and a terrestrial sampling method to fill a critical knowledge gap in how sampling different life stages, and using different sampling methods, provide complementary information and insight into amphibian presence and reproductive success. We used a box trap to sample larval amphibians at approximately 3 -week intervals for 23 months in 8 isolated ephemeral wetlands, and concurrently trapped amphibians using drift fences to: (1) examine spatio-temporal patterns of tadpole occurrence, and developmental stage as metrics of breeding and phenology; (2) explore relationships between breeding effort, tadpole abundance, and recruitment, and; (3) compare the relative efficacy of drift fences to box trap sampling in detecting amphibian species presence (richness) and tracking reproductive outcome. 


\section{Materials and methods}

\section{Study area}

Our study area consisted of 8 small $(0.1-0.37$ ha), isolated wetlands in longleaf pinewiregrass sandhills located in the Ocala National Forest in north-central peninsular Florida. The study wetlands were selected in 1994 as part of an ongoing long-term drift fence study of amphibians using ephemeral wetlands, and can be considered a representative selection of small, ephemeral, groundwater-driven sinkhole wetlands that are common within xeric uplands of the Floridan Aquifer System region. Excessively drained Entisols are underlain by Ocala limestone (Aydelott et al. 1975), resulting in abundant closed depression sinkholes with limited surface drainage networks (Kalisz and Stone 1984). Wetland elevations at their approximate lowest point ranged from 4.0 to $26.2 \mathrm{~m}$ above mean sea level. Average daily temperatures measured were $20.7^{\circ} \mathrm{C}\left(8.9^{\circ} \mathrm{C}-32.5^{\circ} \mathrm{C}\right)$ in 2000 , and $21.3^{\circ} \mathrm{C}\left(10.6^{\circ} \mathrm{C}-32.1^{\circ} \mathrm{C}\right)$ in 2001 . Total precipitation was $130.4 \mathrm{~cm}$ in 2000 and $164.2 \mathrm{~cm}$ in 2001, with > 80\% occurring April - September both years. Heavy precipitation recharging groundwater was associated with thunderstorms in late May - early October, tropical systems in summer and fall, and wet autumn, winter, or spring frontal systems (Winsberg 1990).

\section{Wetland area and depth zone measurements}

We partitioned each wetland into 5 equal wedge-shaped sections by placing a PVC pipe at center, and benchmark rebars at 5 , equally-distanced azimuths $\left(0^{\circ}, 72^{\circ}, 144^{\circ}, 216^{\circ}, 288^{\circ}\right)$ around the perimeter. Basin areas were calculated as a circle $\left(A=\pi r^{2}\right)$, with radius as the 
average distance between center and the 5 rebars. Water surface area (WSA) was measured each sample date (visit) and calculated as a circle using the average of 5 radii $(r)$ from edge to wetland center. We also calculated WSA of 3 concentric depth zones (DZs) (Shaffer et al. 1994), if present. DZ3 ( $\geq 40 \mathrm{~cm}$ ) included WSA from $40 \mathrm{~cm}$ depth to center; DZ2 $(20-39.9 \mathrm{~cm})$ from 20 $\mathrm{cm}$ depth to center, minus area of DZ3; DZ1 $(<20 \mathrm{~cm})$ from water edge to center, minus areas of DZ2 and DZ3. Maximum water depth was measured at wetland centers the same week as box trap sampling dates.

\section{Box trap sampling for larval amphibians}

We used a rigid, open-ended $0.5 \mathrm{~m}^{2}(92 \times 54 \mathrm{~cm} ; 8 \mathrm{~cm} \mathrm{ht}$ ) box trap (Shaffer et al. 1994) to sample tadpoles in all DZs at each wetland at approximately 3-week intervals, from 3 February 2000 - 23 December 2001. The box trap was the same width as our dip net, fitted with green-dipped, $0.95 \mathrm{~cm}$ mesh (Memphis Net and Twine; net Model HDD2). Tadpole sampling entailed pressing the box trap through the water column into the mucky substrate, then removing all tadpoles using repeated dip net sweeps ( $\geq 3$ sweeps until 2 successive sweeps yielded no additional larvae). We avoided dense mats of vegetation that impeded sampling; thus, sampling was biased toward open water. Because wetlands gradually filled or dried, all DZs were not present each visit. Dry wetlands were not sampled and we assumed larvae were absent, although rarely a 'dry' wetland contained small puddles and, potentially, some amphibian larvae or egg masses.

We used a randomized sampling design stratified by DZ, designed to account for spatial variability in tadpole distribution. Each DZ in each of the 5 wetland sections ('wedges') was sampled with one 'throw,' for a total of 15 throws when all 3 DZs were present, or fewer if 
wetlands were shallow. We varied sample locations where possible and observed little if any damage to aquatic vegetation over time. We attempted to maintain at least $4 \mathrm{~m}$ between each 'throw,' but distances were less when WSA was low.

Captured tadpoles were identified to species in the field and scored into 3 developmental classes (Gosner 1960): Class 1: no distinct rear limbs formed (up to Gosner stage 35); class 2: rear limbs formed and discernable toes (Gosner stages 36-41); class 3: $\geq 1$ front limb erupted (Gosner stage 41-46). Larvae were released after processing.

\section{Drift fence sampling for adults and juveniles}

Drift fences, spaced $7.6 \mathrm{~m}$ apart and $7.6 \mathrm{~m}$ in length, encircled $50 \%$ of each wetland perimeter, as part of the longer-term study. Pitfall traps (19-1 buckets) were positioned inside and outside of each fence at both ends, with a funnel trap at fence midpoint on both sides allowing us to ascertain whether amphibians were immigrating to, or emigrating from wetlands. A PVC pipe was placed was between fences to attract treefrogs. Drift fence traps were open continuously and checked approximately 3 times weekly throughout the study period.

Amphibians toe-clipped by wetland number and year, categorized as adult or juvenile based on a specified SVL cutoff for each species (Table 1), and released. Because all wetlands were sampled in proportion to size we did not further adjust for trap nights.

\section{Data analyses}

For each visit, we averaged the number of amphibian larvae per $0.5 \mathrm{~m}^{2} \mathrm{WSA}$ and expanded to number per $\mathrm{m}^{2}$ WSA within each DZ present ( $n=5$ per DZ), then multiplied by the total DZ WSA to estimate total density per DZ; we summed across DZs to estimate total number 
per wetland. Density estimates were based on number per $\mathrm{m}^{2}$ WSA rather than volume, but should accurately represent total numbers within DZs and wetlands, because box traps sampled the entire water column. We examined whether densities of each species differed among DZs when 3 or (separate analysis) 2 DZs were available using repeated measures ANOVAs (Proc Mixed; SAS 9.3; SAS 2009) with wetlands as a random factor.

We examined relationships between adult breeding effort (defined as all first-captured adults), tadpole abundance, and juvenile recruitment (defined as all first-captured juveniles emigrating from ponds) within defined breeding cycles for each species (Table 1). We used longer-term drift fence data for adults captured before, and recruits captured after our larval sampling study period to increase sample size of complete breeding cycles for some species and wetlands. We performed Spearman's correlations to test the relationships between (a) breeding effort and maximum tadpole abundance, and; (b) maximum tadpole abundance and total recruits. Each wetland and breeding cycle was considered an independent observation. Wetlands were included if any adults, tadpoles, or recruits were captured; incomplete breeding cycles were omitted. Correlations were not performed on L. catesbeianus and L. grylio due to inadequate sample size.

We used a paired t-test to compare amphibian richness sampled by box traps and drift fences over the same period. We included Striped Newts (Notophthalmus perstriatus (Bishop, 1941)), in estimates of species richness, but focused only on anurans for other analyses.

\section{Results}


Wetlands 3, 7, and 8 were dry for most of the study period (Fig. 1). In the year 2000, wetlands dried by mid-May through early September, refilling with higher rainfall in September, including Tropical Storm Gordon on 17-18 September which dropped $8.1 \mathrm{~cm}$ of rain. In 2001, all wetlands completely or nearly dried late spring through late September (Fig. 1), refilling after Tropical Storm Gabrielle dropped $28.8 \mathrm{~cm}$ of rain on 14-16 September. WSA was positively correlated with depth $\left(p<0.01 ; r^{2}\right.$ ranged 0.64-0.99); depths and number of DZs corresponded with WSA.

We sampled a total of 3,306 larval amphibians including 12 anuran species, and both larval and paedomorphic N. perstriatus (Table 2; Fig. 2). Because larvae were unmarked, we were unable to determine if individuals were sampled more than once during the study period. Species richness of larval amphibians on any given date, across all wetlands, ranged from 2-10 (Fig. 2). Within wetlands, total richness over the entire study period ranged from 2-11, and generally corresponded with the number of visits a wetland held water (Table 2; Fig. 3). Pinewoods Treefrog (Hyla femoralis (Bosc, 1800)) tadpoles were the most abundant (27.3\%), followed by Florida Gopher Frog (Lithobates (Rana) capito (LeConte, 1855)) (18.6\%), Spadefoot Toad (S. holbrookii (Harlan, 1836)) (16.1\%), and Southern Leopard Frog (L. (Rana) sphenocephalus (Cope, 1886)) (15.6\%) (Table 2). Each wetland was sampled (hence, held water) 2-21 times during the 23-month study period (Table 2).

Most larval amphibian species were detected in only a subset of wetlands over the study period. Only H. femoralis and Little Grass Frog (Pseudacris ocularis (Bosc and Daudin, 1801)) tadpoles were detected at all 8 wetlands; L. capito and L. sphenocephalus were detected at 7, followed by Narrowmouth Toad (Gastrophryne carolinensis (Holbrook, 1835)) and Pig Frog (L. (Rana) grylio (Stejneger, 1901)) (6); Southern Cricket Frog (Acris gryllus (LeConte, 1825)), 
Barking Treefrog (H. gratiosa (LeConte, 1856)), and N. perstriatus (5); American Bullfrog (L. (Rana) catesbeianus (Shaw, 1802)) (4); and S. holbrookii (3) (Table 2; Fig. 3). Oak toad (Anaxyrus (Bufo) quercicus (Holbrook, 1840)) (Dodd 1994; Greenberg and Tanner 2005a) and Southern Toad (A. (Bufo) terrestris (Bonnaterre, 1789)) (Dodd 1994) tadpoles were detected at only one wetland, in September and April 2001, respectively (Table 2; Fig. 3). On any given date, a species detected in $\geq 1$ wetland (e.g., potentially present) was rarely detected in all available (holding water) wetlands (Table 3; Fig. 3). Frequently, species were not detected within available wetlands where they were detected the visit prior, or vice versa (Fig. 3). Most tadpole species were detected intermittently, with apparent disappearances and subsequent reappearance commonly occurring within wetlands and breeding cycles (Fig. 3).

The seasonal timing of tadpole occurrence also differed among some species. Acris gryllus tadpoles were detected in all seasons except winter (mid-November - April). Hyla gratiosa and P. ocularis tadpoles were detected in fall and spring, and H. femoralis tadpoles only in fall - early winter (Table 3; Figs. 3, 4). Gastrophryne carolinensis tadpoles were detected once in each of 4 wetlands during September or October 2000, and on September 2001 in 1 wetland (Table 3; Figs. 3, 4). Lithobates capito and L. sphenocephalus, were detected in $\geq 1$ wetland during most fall-spring months both years; L. grylio and L. catesbeianus were detected most calendar months (Table 3; Figs. 3, 4).

Generally, species with rapid larval development were detected for fewer consecutive visits than those with slow larval development. Acris gryllus, H. gratiosa, P. ocularis, $H$. femoralis, G. carolinensis, S. holbrookii tadpoles, all known to complete development in $\leq 8$ weeks (Ashton and Ashton 1988) were detected for 1-3 consecutive visits within individual wetlands (Fig. 3), and tadpoles in classes 2 or 3 were found within days to weeks of ponds 
refilling (Fig. 4). In contrast, Lithobates spp. tadpoles, which require $\geq 3$ months to $>$ a year to complete development (Ashton and Ashton 1988), were detected on one- to several (L. capito 8, L. sphenocephalus 7, L. grylio 11, L. catesbeianus 3) consecutive visits within individual wetlands (Fig. 3), and class 2 Lithobates tadpoles were first found months after first-detections; no class 3 tadpoles were found during the study period (Fig. 4). Class 2 L. capito and L. sphenocephalus tadpoles were detected in March-April of one or both years, about 6 months after wetlands refilled; additionally, L. capito tadpoles were detected in 1 wetland on November 2000 (Fig. 4). Class 2 L. grylio tadpoles were detected in the months of February, March, April, May, and October, and L. catesbeianus in February 2000 (Fig. 4). Scaphiopus holbrookii tadpoles, all class 1, were detected in 3 wetlands on 19 September 2000, 6-8 days after an explosive breeding event.

When all 3 DZs were available, abundance of L. sphenocephalus was greater in DZ1 than $\mathrm{DZ2}$ or DZ3 $\left(F_{2,15}=6.3 ; p=0.01\right)$; abundance of A. gryllus $\left(F_{2,12}=4.8 ; p=0.03\right)$ and L. capito $\left(F_{2,15}=6.2 ; p=0.01\right)$ was greater in DZ1 than DZ3 (Fig. 5). Abundance of G. carolinensis, $H$. femoralis, P. ocularis, L. catesbeianus, L. grylio, and S. holbrookii did not differ $(p \geq 0.12)$ among DZs when all three were available (Fig. 5). In contrast, abundance of H. gratiosa was higher in DZ3 than DZ1 $\left(F_{2,9}=5.0 ; p=0.03\right)$. When only DZ1 and DZ2 were present, abundance of P. ocularis, L. capito, L. catesbeianus, L. grylio, and L. sphenocephalus did not differ ( $p \geq 0.21)$. Acris gryllus, G. carolinensis, H. femoralis, and H. gratiosa generally occurred only when all three DZs were present. Anaxyrus quercicus and A. terrestris occurred once, and thus data on depth selection were not analyzed.

We found a positive correlation between breeding effort and maximum tadpole abundance for H.femoralis ( $\left.p=0.01 ; r_{\mathrm{s}}=0.61\right)$ and $S$. holbrookii $\left(p=0.01 ; r_{\mathrm{s}}=0.83\right)$, but not 
for the other 8 species tested ( $p \geq 0.17$ ) (Fig. 6). Maximum H. femoralis tadpole abundance was positively correlated with total recruits $\left(p=0.02 ; r_{\mathrm{s}}=0.56\right)$, but we found no relationship for the other 8 species tested $(p \geq 0.19)$ (Fig. 7).

Total amphibian species richness detected by drift fences averaged $( \pm \mathrm{SE}) 4.9 \pm 0.8$ higher $(t=6.18 ; p<0.01)$ than richness detected by box trap sampling.

\section{Discussion}

Our study demonstrates the importance of using both aquatic and terrestrial sampling methods concurrently to more accurately detect amphibian presence and gauge reproductive success. We found that the occurrence, or detectability, of amphibian larvae is highly variable among and within wetlands. Further, the detection of adults or larvae with just aquatic or terrestrial sampling is not a reliable indicator of reproductive success. Use of integrated sampling protocols to accurately detect amphibian presence and population trends is especially important in light of potentially altered weather patterns, wetland hydrology, and amphibian reproductive phenology or outcome associated with climate change (Greenberg et al. 2014, 2015).

Hydroregime was an obvious and important influence on anuran reproductive outcome, but not the sole determining factor. Dry wetlands during both summers prohibited successful breeding and recruitment by exclusively summer-breeding A. quercicus (Dodd 1994; Greenberg and Tanner 2005a) and G. carolinensis (Dodd 1995), and reduced opportunity for other species. Additionally, wetlands dried just prior to potential completion of L. capito and $L$. sphenocephalus metamorphosis and juvenile emigration in late spring-summer (Greenberg 2001) 
of both years, likely resulting in total tadpole mortality and recruitment failure. Similarly, we detected $A$. terrestris, tadpoles in one wetland that dried shortly thereafter, likely resulting in complete mortality.

Stochastic factors other than hydroperiod apparently also caused mortality of entire egg or tadpole cohorts. Even within prolonged hydroperiods detection of individual tadpole species within breeding cycles was spatially and temporally variable. Tadpoles of a given species rarely occurred simultaneously in all available wetlands, and most occurred in a subset of available wetlands throughout the study period. Intermittent detection of tadpole species within continuously filled wetlands suggests high mortality, followed by deposition of eggs resulting in new tadpole cohorts. Other studies have shown high stochastic variation in amphibian reproductive success. Semlitsch et al. (1996) reported that high amphibian recruitment occurred in only 1-7 of 16 years, depending on the species, in South Carolina. Dodd (1994) reported no $A$. quercicus or A. terrestris recruitment from a pond in north-central Florida, over a 5-year period. Greenberg and Tanner (2005a) reported A. quercicus recruitment from 3 of 8 wetlands, in only 2 of 10 years). Richter et al. (2003) reported high variability in the Dusky Gopher Frog (L. (Rana) sevosa (Goin and Netting 1940)) reproductive success in Mississippi, with no consistent relationship between the number of females, eggs, or metamorphs.

Although our study did not elucidate mechanisms for reproductive failure, likely causes were predation or competition within wetlands. Due to frequent drying and isolation from larger water bodies, our study wetlands lacked fish and most predatory aquatic salamander species, including Ambystomids. Notophthalmus perstriatus, the only potentially predatory salamander species detected, is relatively small, gape-limited, and apparently occurred at low densities, likely limiting its impact on tadpoles. On the other hand, wetlands hosted several predatory 
macroinvertebrate species including darner (Aeshnidae) and skimmer (Libuellulidae) dragonfly nymphs, adult and larval predaceous diving beetles (Dytiscidae), giant water bugs (Belostomatidae), creeping water bugs (Naucoridae), and water scorpions (Nepidae) (pers. obs.) that were likely a primary source of mortality.

We found no consistent relationship between apparent anuran breeding effort and tadpole abundance, or between tadpole abundance and recruitment for most species. Aside from stochastic factors, reasons may include: (1) tadpoles may be present but go undetected; this likelihood may be higher for species that exhibit schooling behavior; (2) adult captures during breeding seasons are not necessarily indicative of breeding; others have noted that anuran calling does not always correspond with breeding and egg deposition (D. Saenz pers. comm.); (3) primarily aquatic species, such as A. gryllus and L. grylio, inhabit wetlands year-round; thus, drift fence captures may not be indicative of breeding; (4) adult or juvenile capture rates may be unreliable indicators of breeding effort or recruitment, respectively, due to trap evasion or escape. For example, adult A. gryllus, P. ocularis, and Hylid spp. can potentially climb out of pitfall traps (Dodd 1991), and large Lithobates spp. adults can potentially jump out of pitfall traps or evade fences entirely (Pechmann et al. 1989; Semlitsch et al. 1996). Similarly, juvenile A. gryllus, P. ocularis, and H. gratiosa, can potentially climb from pitfall traps (Pechmann 1989); juvenile Lithobates spp. are generally unable to jump from pitfall traps (Pechmann et al. 1989; pers. obs.); (5) relatively few adults could potentially contribute to large numbers of tadpoles; consistently low adult capture rates of all 4 Lithobates spp. suggested this as an alternative explanation to trap escape or evasion; (6) adults, such as $A$. quercicus, $G$. carolinensis, and $A$. terrestris, migrate to dry wetlands during breeding season, without potential for reproductive success. 
Habit or reproductive strategy could partially account for the few positive relationships we observed among breeding effort, tadpole abundance, and juvenile recruitment. Adult $H$. femoralis captures were generally greater at wetlands with water, thereby increasing the likelihood of tadpole occurrence in those wetlands. Similarly, the positive correlation between $H$. femoralis tadpole abundance and juvenile recruitment was likely influenced by increased capture probability of new recruits using PVC pipes as refugium for protracted periods. The explosive breeding habit by $S$. holbrookii, with dozens- to hundreds of adults breeding simultaneously (Greenberg and Tanner 2004, 2005b) could decrease the likelihood of complete cohort mortality in all wetlands where breeding occurred. Even then, apparent mortality of entire egg or tadpole cohorts was common; S. holbrookii tadpoles were detected in only 3 of 5 wetlands where explosive breeding occurred in 2000, and in none of the 4 wetlands where explosive breeding occurred in 2001 (see Greenberg and Tanner 2004, 2005b).

Our results indicate that non-detection of a given tadpole species does not necessarily indicate that adults were absent, or did not breed, within a given year or wetland, and highlights the complementary information yielded by using both aquatic and terrestrial sampling methods. Werner et al. (2007b) found high inter-annual variability in tadpole species occurrence among multiple wetlands in Michigan, with only half of the expected species detected in any given year. Our findings suggest that their results could be partially attributed to 8-9 week intervals between their May and July visits, potentially resulting in missed detections of spatially and temporally intermittent tadpole occurrences. Our results highlight the importance of box trap sampling frequently and concurrently at multiple wetlands for monitoring species presence, since detectability and presence of larval amphibians frequently 'blinks' on and off among sampling dates and wetlands. 
Our study illustrates difficulties in comparing results of drift fence and aquatic sampling due to inherent biases of both methods. Drift fences detected more amphibian species than box trap sampling at regular intervals, likely in part because they were continuously open. Additionally, non-aquatic-breeding species such as the Greenhouse Frog (Eleutherodactylus planirostris (Cope, 1862)), Dwarf Salamander (Eurycea quadridigitata (Holbrook, 1842)), and Slimy Salamander (P. grobmani (Allen and Neil, 1949)) are likely to be detected only by drift fences. Further, some species such as the Green Treefrog (H. cinerea (Schneider, 1799)) and Southern Chorus Frog (P. nigrita (LeConte, 1825)), may be present in surrounding uplands, but fail to breed every year and thus go undetected by box traps. Moreover, wetlands may be dry during the majority of breeding season for some species, such as A. quercicus, A. terrestris, and G. carolinensis in our study, and thus undetected by aquatic sampling. Further, species with rapid developmental rate, such as $S$. holbrookii, can be missed by box traps if sampling intervals are too infrequent to detect tadpoles before metamorphosis. Similarly, rapid, complete mortality of eggs or tadpoles could result in species being missed by box trap sampling at 3-week intervals.

Other studies also indicate that amphibian species detections in wetlands are maximized when multiple sampling methods are used at suitable frequencies in relation to interspecific differences in temporal calling patterns, breeding periods, and larval presence (Dodd 2009). Our results additionally illustrate the utility of drift fences in detecting species presence and, perhaps more importantly, apparent breeding effort, and recruitment, for many species. On the other hand, aquatic sampling can detect presence and relative abundance of amphibian larvae. We found that amphibian monitoring methods designed to detect only breeding activity (e.g., 
acoustic methods) or larvae (e.g., box traps, dip nets), are not reliable indicators of successful recruitment.

Tadpole occurrence in newly-filled wetlands in September of both years provided a known approximate 'start' date for egg and tadpole phenology. Presence of class 1 and 2 ( $G$. carolinensis, P. ocularis), or 1, 2, and 3 (A. gryllus, H. femoralis, H. gratiosa) shortly after wetlands refilled indicated rapid developmental rates. Tadpoles of all 4 Lithobates spp. were sampled sporadically, but were present intermittently in $\geq 1$ wetlands during some late fallthrough early spring months; L. grylio and L. catesbeianus were also present in some summer months. The presence of class 1 and 2 L. grylio in February - May and October suggested its potential to breed intermittently and metamorphose year-round. Although L. catesbeianus tadpoles can take $\geq 1$ year to fully develop, we detected them in individual wetlands for short periods (maximum 9 weeks); most were class 1 regardless of month sampled, suggesting that intermittent breeding with introduction of new cohorts, and high mortality occurred throughout much of the year. Lithobates capito and L. sphenocephalus tadpoles were detected intermittently in some wetlands, but continuously in others for about 5 (L. sphenocephalus) or 6 (L. capito) fall-late spring months; class 2 tadpoles were present only during spring months (except at 1 wetland, where class 2 L. capito tadpoles were detected in November). This suggests that both species can breed intermittently during fall - spring, and younger tadpole cohorts may accelerate development during spring, for a relatively synchronous late spring - summer metamorphosis and emigration by all cohorts (Palis 1998; Greenberg 2001). Scaphiopus holbrookii juvenile emigration peaked 16-18 days after an explosive breeding event (29 September-4 October 2000), confirming that larval development was complete within 2.5-4 weeks. 
Our results suggest that breeding periods vary somewhat among locations and years. We detected A. gryllus tadpoles in all seasons except winter, although they are winter-breeders in central Florida (Babbitt and Tanner 2000). We detected H. femoralis in September-December, and H. gratiosa in fall and spring; Babbitt and Tanner (2000) reported that both species breed only in summer, in central Florida. Pseudacris ocularis bred during fall - early winter, and again in spring, whereas Babbitt and Tanner (2000) reported they breed year-round in central Florida. In our study Lithobates spp. showed temporal patterns consistent with fall-winter-spring $(L$. capito and L. sphenocephalus) or year-round (L. grylio, L. sphenocephalus) breeding and tadpole development. Palis (1998) reported that L. capito breeds intermittently October - May in the Florida panhandle, whereas L. sphenocephalus breeds in winter, spring, and summer (Ashton and Ashton 1988) or year-round (Babbitt and Tanner 2000).

We found that A. gryllus, L. capito, and L. sphenocephalus selected shallow water $(<40$ $\mathrm{cm})$ and $H$. gratiosa deeper water $(\geq 40 \mathrm{~cm})$ when choices were available. Other species exhibited no depth preference. We did not measure water temperature or dissolved oxygen, but suggest that DZ selection could reflect preference for either or both; generally, temperatures are higher, and dissolved oxygen lower in shallow water (e.g., Noland and Ultsch 1981). Additionally, differences in species' distribution among DZs could potentially reduce interspecific competition through resource partitioning (e.g., Whiting 2010). Several studies indicate that reduced competition (Wilbur 1982; Morin 1983) and higher water temperatures increase survival, growth, and developmental rate of tadpoles (e.g., Blaustein et al. 2010). In addition, most species were sampled in wetlands $<20 \mathrm{~cm}$ depth, illustrating that ephemeral, shallow wetlands can nonetheless provide reproductive opportunity for many amphibian species. 
Our results illustrate shortfalls in the ability of infrequent aquatic sampling to detect local species richness of larval amphibians, as the occurrence of many species is spatially and temporally variable. Additionally, we show the importance of using different sampling methods to detect species' presence, and difficulties associated with both methods in tracking breeding effort, tadpole occurrence, or reproductive outcome.

\section{Acknowledgments}

Funding for this study was provided by the Florida Fish and Wildlife Conservation Commission contracts NG99-014 under permit no. WV99207. This research was approved by the University of Florida Animal Care and Use Protocol \#4061. We thank J. Beach (deceased), J. Staiger, T. Smith (deceased), G. Smith, R. Ashton, D. Johnson, G.W. Tanner, and many others for their assistance. We also thank L. Lowery, R. Lowery, C. Sekerak, J. Hinchee, J. Clutts, and the US Forest Service fire crew for assistance. Stanley Zarnoch provided guidance on statistical analyses. Suggestions by two anonymous reviewers helped to improve an earlier version of this manuscript. This article is dedicated to Joan Beach, Gracie, and Croaker. 


\section{References}

Aydelott, D.G., Bullock, H.C., Furman, A.L., White, H.W., and Spieth, J.W. 1975. Soil survey of Ocala National Forest area, Florida. United States Government Printing Office, Washington, D.C.

Ashton, R.E. Jr., and Ashton, P.S. 1988. Handbook of Reptiles and Amphibians of Florida, Part Three: The Amphibians. Windward Publishing, Incorporated, Fla.

Babbitt, K. J., and Tanner, G.W. 2000. Use of temporary wetlands by anurans in a hydrologically modified landscape. Wetlands, 20: 313-322.

Blaustein, A.R., Walls, S.C., Bancroft, B.A., Lawler, J.J., Searle, C.L., and Gervasi, S.S. 2010. Direct and indirect effects of climate change on amphibian populations. Diversity, 2010: $281-313$.

Collins, J.P., and Storfer, A. 2003. Global amphibian declines: Sorting the hypotheses. Divers. Distrib. 9: 89-98.

Dodd, C.K., Jr. 1991. Drift fence-associated sampling bias of amphibians at a Florida sandhills temporary pond. J. Herpetol. 25: 1991. 
Dodd, C.K., Jr. 1994. The effects of drought on population structure, activity, and orientation of toads (Bufo quercicus and B. terrestris) at a temporary pond. Ethol. Ecol. Evol. 6: 331349.

Dodd C.K., Jr. 1995. The ecology of a sandhills population of the eastern narrow-mouthed toad, Gastrophryne carolinensis, during a drought. Bull. Florida Mus. Nat. Hist., Biol. Sci. 38, Pt. 1: 11-41.

Dodd, C.K., Jr. (editor). 2009. Amphibian ecology and conservation: A handbook of techniques. Oxford University Press, England.

Gosner, K.L. 1960. A simplified table for staging anuran embryos and larvae with notes on identification. Herpetologica, 16: 183-190.

Greenberg, C.H. 2001. Spatio-temporal dynamics of pond use and recruitment in Florida gopher frogs (Rana capito aesopus). J. Herpetol. 35: 74-85.

Greenberg, C.H., and Tanner, G.W. 2004. Breeding pond selection and movement patterns by eastern spadefoot toads (Scaphiopus holbrookii) in relation to weather and edaphic conditions. J. Herpetol. 38: 569-577.

Greenberg, C. H., and Tanner, G.W. 2005a. Spatial and temporal ecology of oak toads (Bufo quercicus) on a Florida landscape. Herpetologica, 61: 422-434. 
Greenberg, C. H., and Tanner, G.W. 2005b. Spatial and temporal ecology of eastern spadefoot toads on a Florida landscape. Herpetologica, 61: 20-28.

Greenberg C. H., Perry, R.W., Franzreb, K.E., Loeb, S.C., Saenz, D., and Rudolph, D.C. 2014. Climate change and wildlife in the southern United States: Potential effects and management options. In Climate Change Adaptation and Mitigation Management Options. Edited by J.M. Vose and K.D. Klepzig. CRC Press, N.Y. pp. 379-420.

Greenberg C.H., Goodrick, S., Austin, J.D., and Parresol, B.R. 2015. Hydroregime prediction models for ephemeral groundwater-driven sinkhole wetlands: A planning tool for climate change and amphibian conservation. Wetlands, 35: 899-911.

Kalisz, P.J., and Stone, E.L. 1984. The longleaf pine islands of the Ocala National Forest, Florida: A soil study. Ecology, 65: 1743-1754.

Miller, D.A., Nichols, J.D., McClintock, B.T., Grant, E.H.C., Bailey, L.L., and Weir, L.A. 2011. Improving occupancy estimation when two types of observational error occur: nondetection and species misidentification. Ecology, 92: 1422-1428.

Morin, P.J. 1983. Predation, competition, and the composition of larval anuran guilds. Ecol. Monogr. 53: 119-138. 
Noland, R., and Ultsch, G.R. 1981. The roles of temperature and dissolved oxygen in microhabitat selectin by the tadpoles of a frog (Rana pipiens) and a toad (Bufo terrestris). Copeia, 1981: 645-652.

Palis, J.G. 1998. Breeding biology of the gopher frog, Rana capito, in western Florida. J. Herpetol. 32: 217-223.

Pearman, P.B. 1995. Effects of pond size and consequent predator density on two species of tadpoles. Oecologia, 102: 1-8.

Pechmann, J.H.K., Scott, D.E., Gibbons, J.W., and Semlitsch, R.D. 1989. Influence of wetland and hydroperiod on diversity and abundance of metamorphosing juvenile amphibians. Wetl. Ecol. Manage. 1: 3-11.

Richter S.C., Young, J.E., Johnson, G.N., and Seigel, R.A. 2003. Stochastic variation in reproductive success of a rare frog, Rana sevosa: Implications for conservation and for monitoring amphibian populations. Biol. Conserv. 111: 171-177.

SAS Institute Inc. 2009. SAS/STAT ${ }^{\circledR}$ User's Guide Version 9.2, second edition. SAS Institute Inc., Cary, N.C.

Semlitsch, R.D., Scott, D.E., Pechmann, J.H.K., and Gibbons, J.W. 1996. Structure and dynamics of an amphibian community: Evidence from a 16-year study of a natural pond. 
In Long-term Studies of Vertebrate Communities. Edited by M.L. Cody and J.A. Smallwood. Academic Press, Cal. pp. 217-248.

Semlitsch, R.D., Peterman, W.E., Anderson, T.L., Drake, D.L., and Ousterhout, B.H. 2015. Intermediate pond sizes contain the highest density, richness, and diversity of pondbreeding amphibians. PLoS ONE, 10(4): e0123055. https://doi.org/10.1371/journal.pone.0123055

Skelly, D.K. 1997. Tadpole communities: Pond permanence and predation are powerful forces shaping the structure of tadpole communities. Am. Sci. 85: 36-45.

Skelly, D. K., Yurewicz, K.L., Werner, E.E., and Relyea, R.A. 2003. Estimating decline and distributional change in amphibians. Conserv. Biol. 17: 744-751.

Shaffer, H.B., Alford, R.A., Woodward, B.D., Richards, S.J., Altig, R.G., and Gascon, C. 1994. Quantitative sampling of amphibian larvae. In Measuring and Monitoring Biological Diversity: Standard Methods for Amphibians. Edited by W.R. Heyer, M.A. Donnelly, M. Foster and R. McDiarmid. Smithsonian Institution Press, Washington, D.C. pp. 130141.

Snodgrass J.W., Komoroski, M.J., Bryan, A.L., Jr, and Burger, J. 2000. Relationships among isolated wetland size, hydroperiod, and amphibian species richness: implications for wetland regulations. Conserv. Biol. 14: 414-419. 
Trenham, P.C., Koenig, W.D., Mossman, M.J., Stark, S.L., and Jagger, L.A. 2003. Regional dynamics of wetland-breeding frogs and toads: turnover and synchrony. Ecol. Appl. 13: 1522-1532.

Werner, E.E., Skelly, D.K., Relyea, R.A., and Yurewicz, K.L. 2007a. Amphibian species richness across environmental gradients. Oikos, 116: 1697-1712.

Werner, E.E., Yurewicz, K.L., Skelly, D.K., and Relyea, R.A. 2007b. Turnover in an amphibian metacommunity: The role of local and regional factors. Oikos, 116: 1713-1725.

Whiting, A.V. 2010. Factors affecting larval growth and development of the boreal chorus frog Pseudacris maculata. PhD thesis, Department of Biological Sciences, University of Alberta, Canada.

Wilbur, H.M. 1982. Competition between tadpoles of Hyla femoralis and Hyla gratiosa in laboratory experiments. Ecology, 63: 278-282.

Winsberg, M.D. 1990. Florida Weather. University of Central Florida Press, Fla. 
Table 1. Time intervals used to define breeding effort (total first-captured adults) and recruitment (juveniles exiting from wetlands) based on drift fence sampling, and snout-vent length (SVL) cutoffs used to designate adults and recruits.

\begin{tabular}{|c|c|c|c|}
\hline Species & Adult breeding effort & Juvenile emigration & Juvenile SVL (mm) \\
\hline Acris gryllus & Intermittent $^{a}$ & Intermittent $^{b}$ & $<15$ \\
\hline Anaxyrus quercicus & May, week 1 - Oct Week 4 & Jun week 1 - Dec week 4 & $<20$ \\
\hline Anaxyrus terrestris & Feb, week 1 - Oct Week 4 & Mar week 4 - Dec week 4 & $<25$ \\
\hline Gastrophryne carolinensis & May week 1 - Oct week 4 & Jun week 1 - Dec week 4 & $<23$ \\
\hline Hyla femoralis & May week 1 - Oct week 4 & Sept week 1 - August week $4^{c}$ & $<24$ \\
\hline Hyla gratiosa & Intermittent $^{a}$ & Intermittent $^{b}$ & $<40$ \\
\hline Pseudacris ocularis & Intermittent $^{a}$ & Intermittent ${ }^{b}$ & $<12$ \\
\hline Lithobates capito & May week 1 - April week 4 & Apr week 1 - Oct week 4 & $<50$ \\
\hline L. catesbeianus & May week 1 - April week 4 & Apr week 4 - Dec week 4 & $<59$ \\
\hline L. grylio & Intermittent $^{a}$ & Intermittent ${ }^{b}$ & $<56$ \\
\hline L. sphenocephalus & May week 1 - April week 4 & Apr week 4 - Dec week 4 & $<52$ \\
\hline
\end{tabular}


Table 1, continued

S. holbrookii ${ }^{d}$

If $\geq 30$ within 1 week $^{d}$

12 weeks after breeding event ${ }^{e}$

$<18$

${ }^{a}$ Sum of adult captures during the interval starting when prior tadpole cohort is no longer detected in wetland, until the new cohort (resulting from that breeding effort) is first detected, and until that cohort is no longer detected.

${ }^{b}$ Sum of exiting juvenile captures starting when a new cohort of tadpoles is first detected in a wetland, through the period when that cohort is no longer detected, and until the next, new cohort of tadpoles is first detected.

${ }^{c}$ Sum of exiting juvenile captures starting in September when tadpoles first detected, until the following August, or until wetland dries and then refills for opportunity for new breeding/cohort.

${ }^{d}$ Explosive breeding events.

${ }^{e}$ Tadpoles metamorphose within 3 weeks of explosive breeding events, so we used a longer time period to include emigrating juvenile 'stragglers.' 
Table 2. Total number of amphibian larvae, times sampled (wetlands not sampled if dry), and number of box trap throws ( 5 per 3 depth zones when present, per visit). Wetlands containing water were sampled at approximately 3-week intervals 3 February $2000-23$ December 2001 at 8 small, ephemeral wetlands in the Ocala National Forest, Florida

\section{Wetland Number}

Species

Acris gryllus

Anaxyrus quercicus

A. terrestris

Gastrophryne carolinensis

Hyla femoralis

H. gratiosa

Notophthalmus perstriatus

Pseudacris ocularis

Lithobates capito

L. catesbeianus

L. grylio

L. sphenocephalus

Scaphiopus holbrookii

Total larvae sampled

Total species sampled

Total times wetland sampled 2

$11 \quad 14$

0

0

4

0

4

0

0

59

$\begin{array}{lllll}6 & 7 & 8 & \text { Total }\end{array}$

$0 \quad 0$

0

$\begin{array}{llll}8 & 0 & 2 & 94\end{array}$

$1=-1$

56

$\begin{array}{lllll}0 & 0 & 0 & 0 & 4 \\ 0 & 0 & 0 & 0 & 56\end{array}$

$\begin{array}{lllll}5 & 15 & 0 & 0 & 23\end{array}$

$\begin{array}{lllllllll}185 & 159 & 8 & 77 & 167 & 179 & 10 & 118 & 903\end{array}$

$\begin{array}{lllllllll}25 & 1 & 0 & 14 & 32 & 1 & 0 & 0 & 73\end{array}$


$\begin{array}{llllllllll}\text { Total } 0.5 \mathrm{~m}^{2} \text { box trap throws } & 235 & 230 & 35 & 155 & 250 & 200 & 15 & 60 & 1180\end{array}$ 
Table 3. Number of 8 total study wetlands with water on each visit, and number of wetlands where each larval amphibian species was detected with box trap sampling at approximately 3-week intervals, February 2000-December 2001, Ocala National Forest, Florida.

\section{SPECIES $^{a}$}

\section{DATE H2O AGRY AQUE ATER GCAR HFEM HGRA NPER POCU LCAP LCAT LGRY LSPH SHOL}

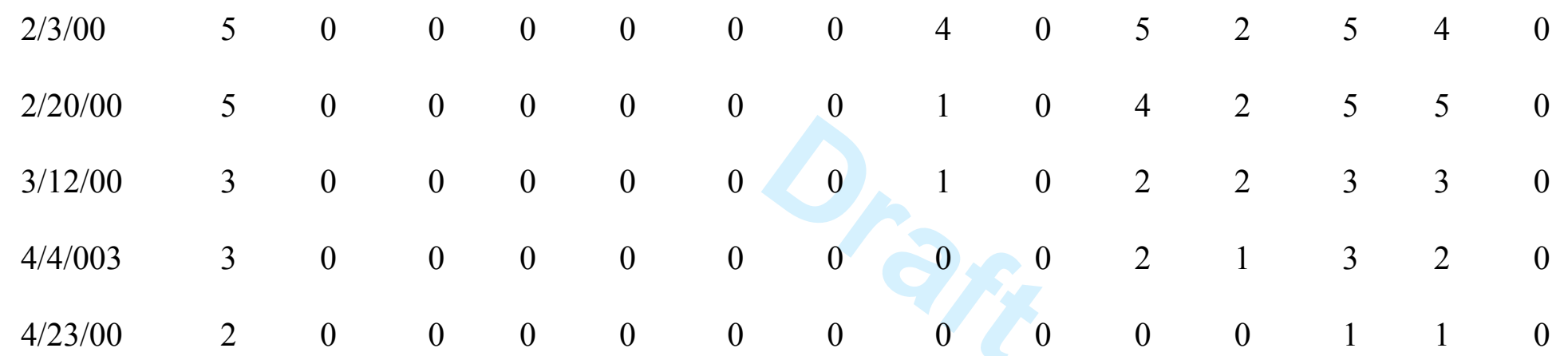

[AFTER 4/23/00 ALL WETLANDS DRY; NEXT VISIT WITH WATER ON 9/19/00]

$\begin{array}{lllllllllllllll}9 / 19 / 00 & 6 & 3 & 0 & 0 & 2 & 5 & 3 & 0 & 2 & 0 & 0 & 2 & 0 & 3 \\ 10 / 15 / 00 & 6 & 2 & 0 & 0 & 2 & 6 & 1 & 0 & 2 & 4 & 0 & 2 & 1 & 0 \\ 11 / 15 / 00 & 5 & 0 & 0 & 0 & 0 & 2 & 1 & 0 & 0 & 4 & 0 & 2 & 1 & 0 \\ 11 / 28 / 00 & 5 & 0 & 0 & 0 & 0 & 1 & 0 & 0 & 1 & 4 & 0 & 2 & 3 & 0 \\ 12 / 17 / 00 & 5 & 0 & 0 & 0 & 0 & 0 & 0 & 0 & 1 & 2 & 0 & 3 & 5 & 0 \\ 1 / 9 / 01 & 5 & 0 & 0 & 0 & 0 & 0 & 0 & 0 & 0 & 4 & 0 & 2 & 3 & 0\end{array}$




$\begin{array}{lllllllllllllll}1 / 28 / 01 & 5 & 0 & 0 & 0 & 0 & 0 & 0 & 0 & 0 & 4 & 0 & 1 & 3 & 0 \\ 2 / 17 / 01 & 5 & 0 & 0 & 0 & 0 & 0 & 0 & 0 & 0 & 3 & 0 & 2 & 3 & 0 \\ 3 / 28 / 01 & 5 & 0 & 0 & 0 & 0 & 0 & 0 & 0 & 0 & 2 & 0 & 1 & 3 & 0 \\ 4 / 21 / 01 & 4 & 0 & 0 & 1 & 0 & 0 & 3 & 1 & 2 & 2 & 1 & 1 & 2 & 0 \\ 5 / 21 / 01 & 1 & 1 & 0 & 0 & 0 & 0 & 1 & 1 & 1 & 0 & 0 & 1 & 1 & 0 \\ 6 / 8 / 01 & 4 & 1 & 0 & 0 & 0 & 0 & 0 & 1 & 0 & 0 & 0 & 0 & 0 & 0 \\ 7 / 12 / 01 & 3 & 1 & 0 & 0 & 0 & 0 & 0 & 0 & 0 & 0 & 1 & 1 & 0 & 0 \\ 8 / 5 / 01 & 4 & 0 & 0 & 0 & 0 & 0 & 0 & 0 & 0 & 0 & 0 & 0 & 0 & 0\end{array}$

[ALL WETLANDS DRY; NEXT VISIT WITH WATER ON 9/26/01]

\begin{tabular}{|c|c|c|c|c|c|c|c|c|c|c|c|c|c|c|}
\hline $9 / 26 / 01$ & 8 & 4 & 1 & 0 & 1 & 6 & 1 & 1 & 7 & 5 & 0 & 2 & 1 & 0 \\
\hline $10 / 26 / 01$ & 8 & 3 & 0 & 0 & 0 & 7 & 1 & 1 & 5 & 6 & 1 & 2 & 4 & 0 \\
\hline $11 / 23 / 01$ & 7 & 0 & 0 & 0 & 0 & 1 & 0 & 0 & 0 & 4 & 4 & 3 & 4 & 0 \\
\hline $12 / 23 / 01$ & 6 & 1 & 0 & 0 & 0 & 1 & 0 & 0 & 1 & 5 & 4 & 2 & 3 & 0 \\
\hline
\end{tabular}

${ }^{a}$ Agry $=$ A. gryllus $;$ Aque $=$ A. quercicus $;$ Ater $=$ A. terrestris $;$ Gcar $=$ G. carolinensis $;$ Hfem=H. femoralis $;$ Hgra=H. gratiosa $;$ Nper=N. perstriatus; Pocu=P. ocularis; Lcap=L. capito; Lcat=L. catesbeianus; Lgry=L. grylio; Lsph=L. sphenocephalus; Shol=S. holbrookii 


\section{LIST OF FIGURES}

Figure 1. Total water surface area, and surface area of 3 depth zones $(<20 \mathrm{~cm} ; 20-39.9 \mathrm{~cm} ; \geq 40$ $\mathrm{cm})$ in 8 isolated ephemeral wetlands sampled at approximately 3 -week intervals $(2 / 3 / 2000-$ 12/23 2001), Ocala National Forest, Florida.

Figure 2. Species occurrence of amphibian larvae in one or more of 8 study wetlands, based on box trap samples taken at approximately 3 -week intervals (2/3/2000-12/23/2001), Ocala National Forest, Florida. Samples were not taken if wetland(s) were dry or nearly dry.

Figure 3. Estimated number of amphibian larvae per wetland based on box trap samples taken at approximately 3 -week intervals from 8 isolated ephemeral wetlands (2/3/2000 - 12/23/2001), Ocala National Forest, Florida. Samples were not taken if wetland(s) were dry or nearly dry.

Figure 4. Average proportion of tadpoles in developmental classes 1, 2, or 3 sampled using box traps at approximately 3 -week intervals $(2 / 3 / 2000-12 / 23 / 2001)$ at 8 isolated ephemeral wetlands, Ocala National Forest, Florida. Samples were not taken if wetland(s) were dry or nearly dry. Average proportions for each visit and species include only wetlands where larvae of respective species were sampled.

Figure 5. Average density (number per $\mathrm{m}^{2}$ water surface area) of amphibian larval species in each of 3 water depth zones (DZs) based on box trap samples taken at approximately 3-week intervals (2/3/2000-12/23/2001) in each of 8 isolated ephemeral wetlands, Ocala National Forest, 
Florida. Averages are based on visits and wetlands when all 3 DZs were present and larvae of respective species were detected. Different letters among DZs denote significantly different densities within species.

Figure 6. Results of Spearman's correlations between adult anuran first-captures, sampled with drift fences (assumed breeding effort), and maximum estimated number of tadpoles, sampled with box traps, per wetland and breeding cycle, at 8 isolated ephemeral wetlands, Ocala National Forest, Florida. Rho $\left(r_{\mathrm{s}}\right)$ is presented only if $P<0.05$. Correlations could not be performed on L. catesbeianus and L. grylio due to inadequate sample size.

Figure 7. Results of Spearman's correlations between maximum estimated number of tadpoles, sampled with box traps, and number of first captured juvenile recruits exiting wetlands, sampled with drift fences, per wetland and breeding cycle, at 8 isolated ephemeral wetlands, Ocala National Forest, Florida. Rho $\left(r_{\mathrm{s}}\right)$ is presented only if $P<0.05$. Correlations could not be performed on L. catesbeianus and L. grylio due to inadequate sample size. 

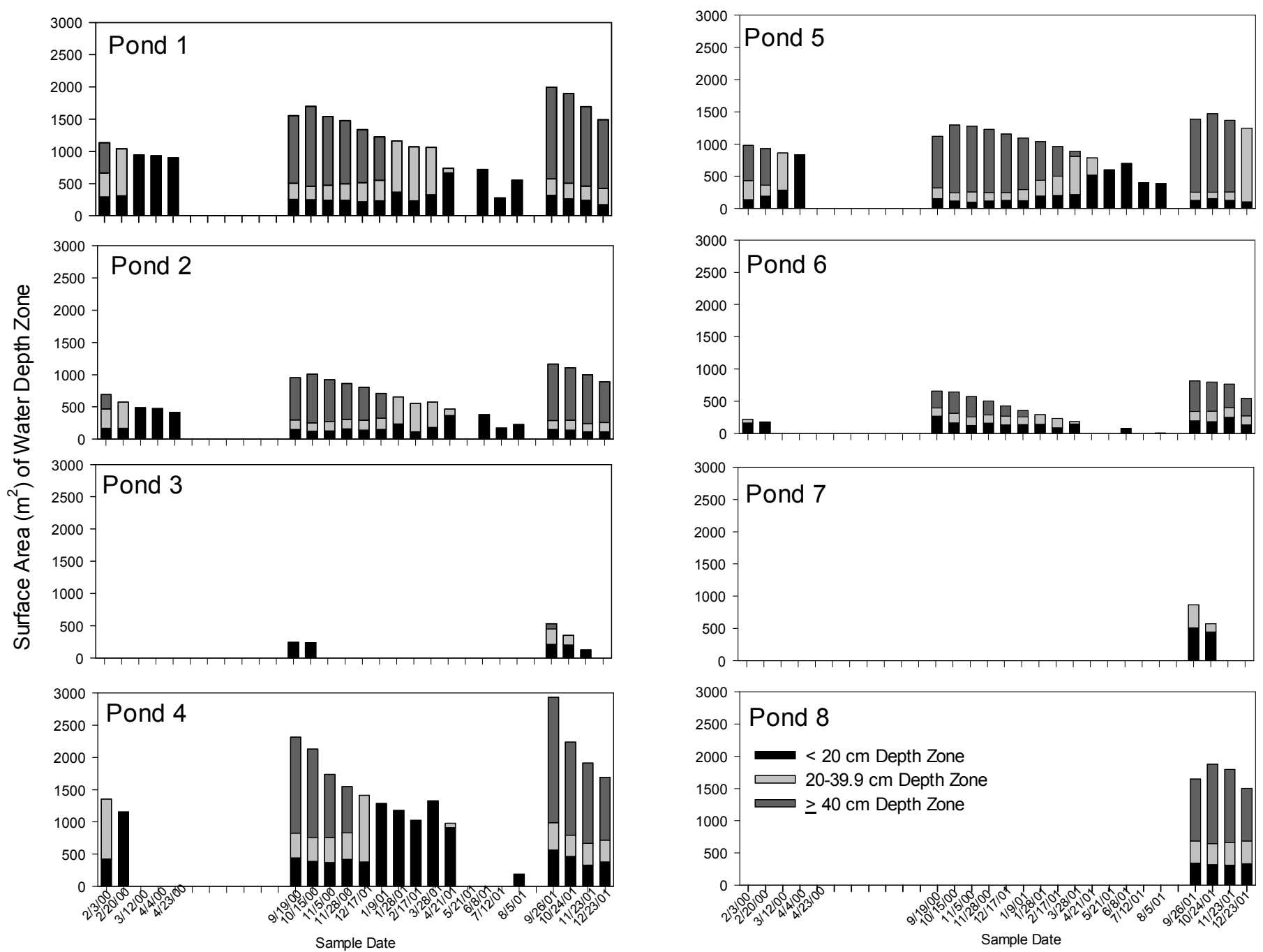


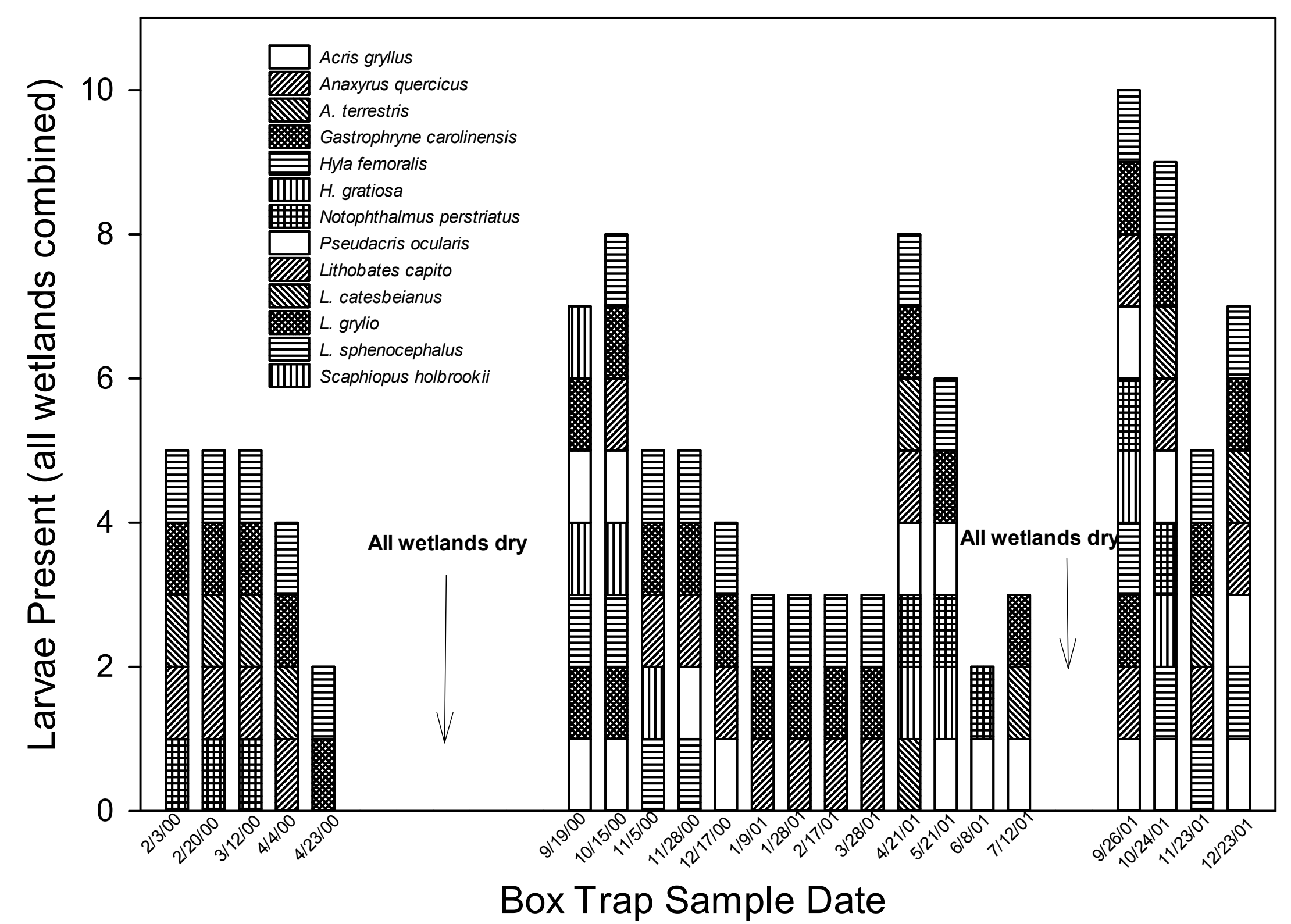




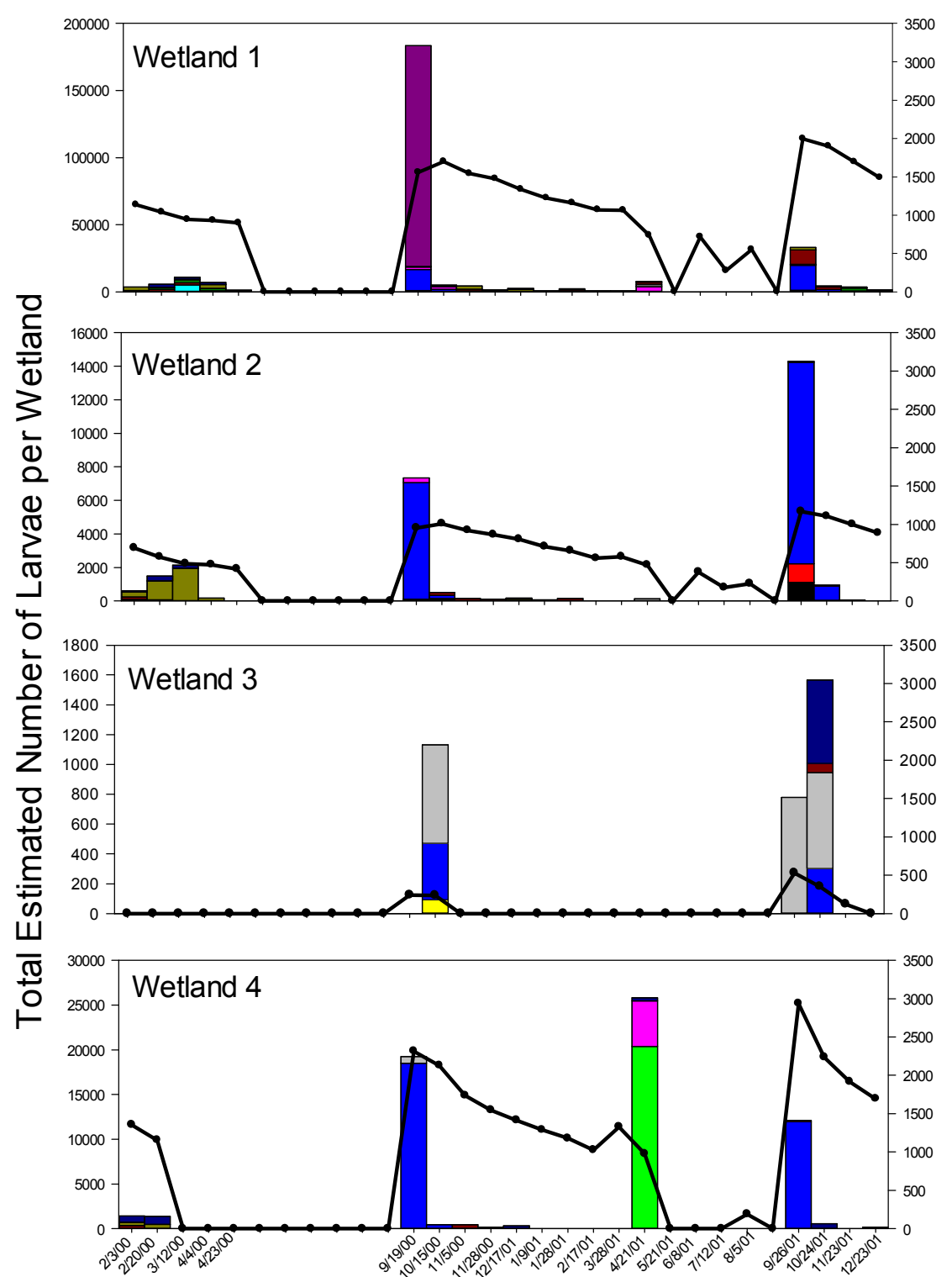

Box Trap Sample Date
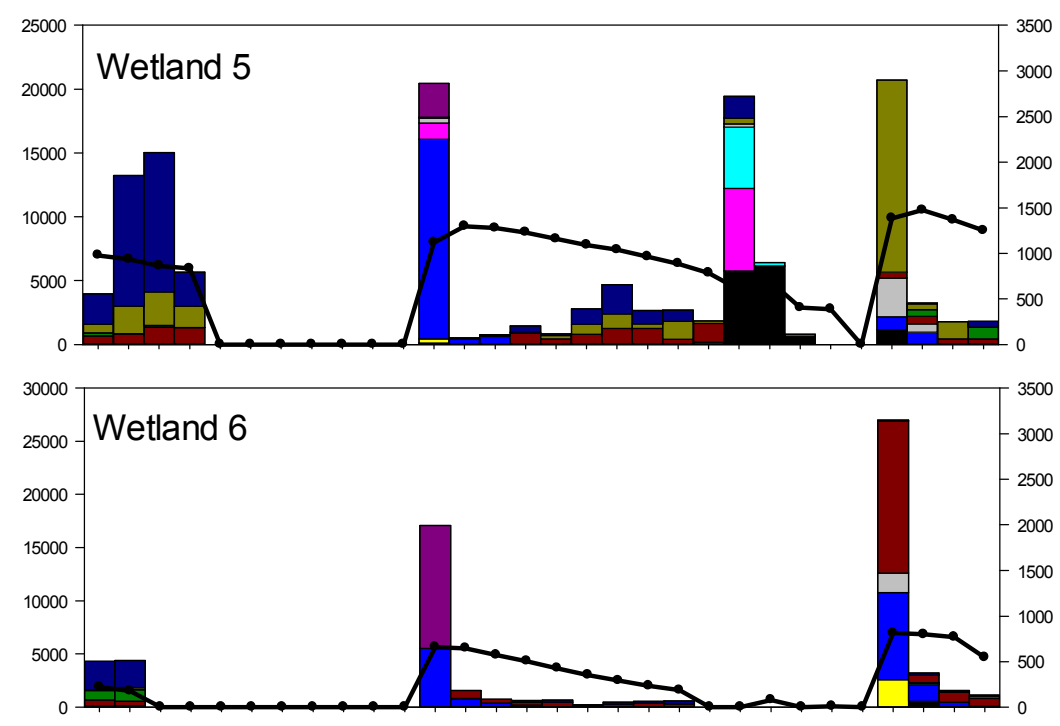

드
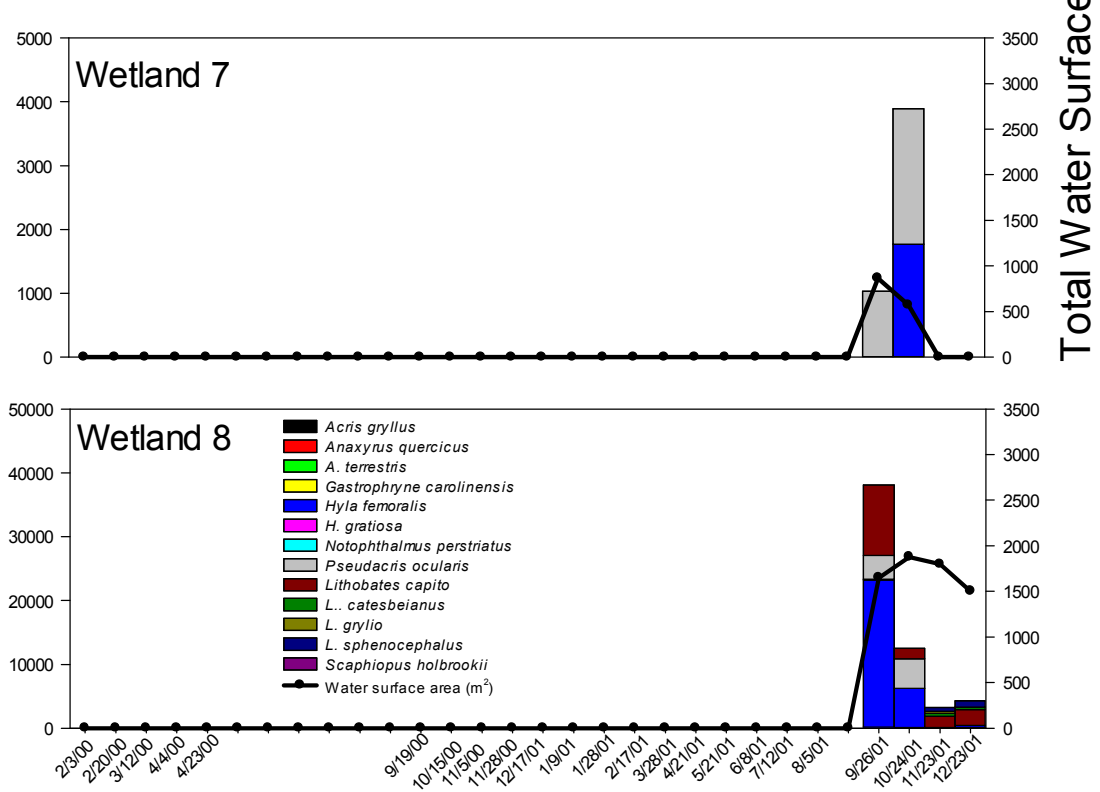

Box Trap Sample Date 


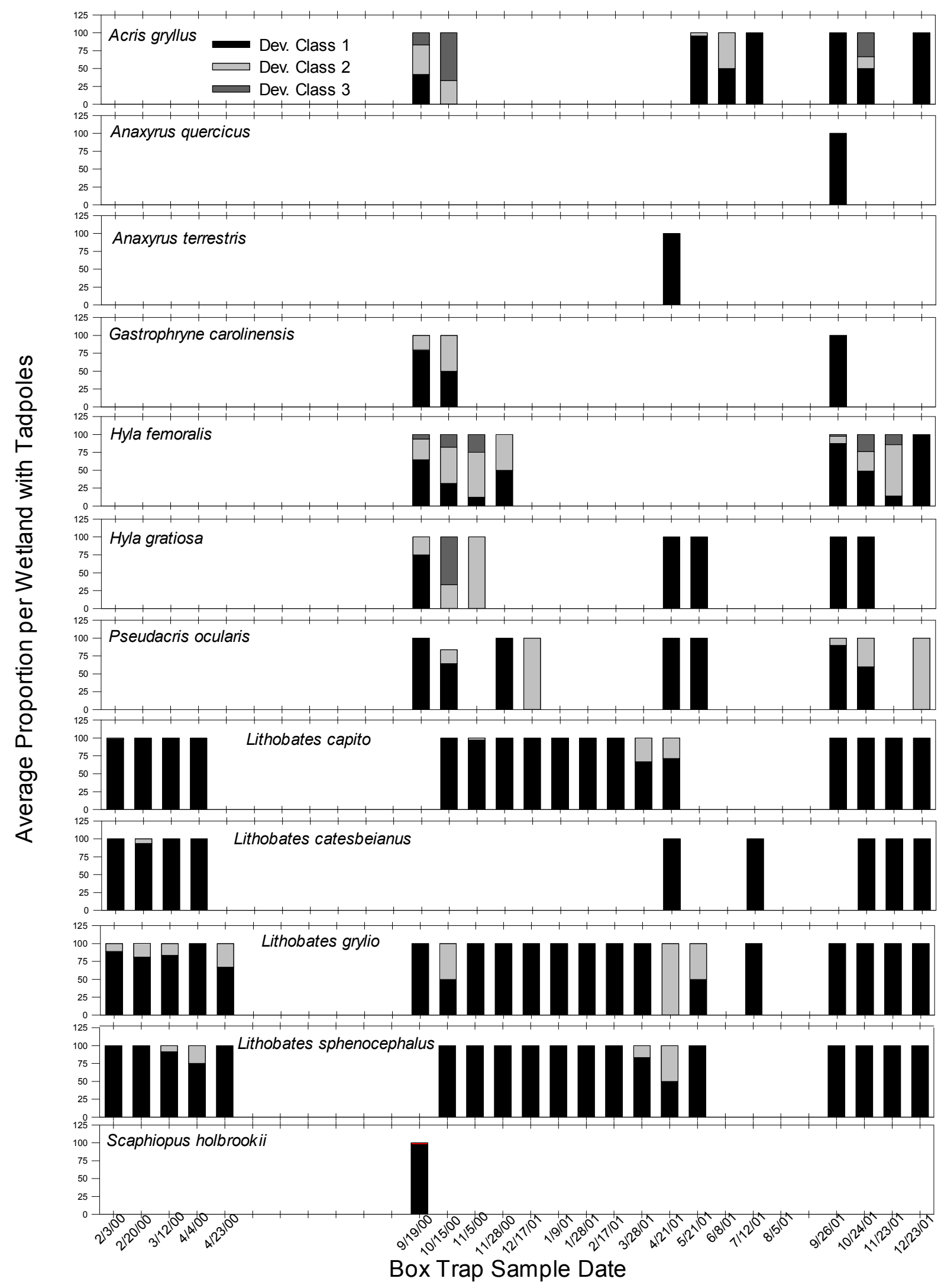




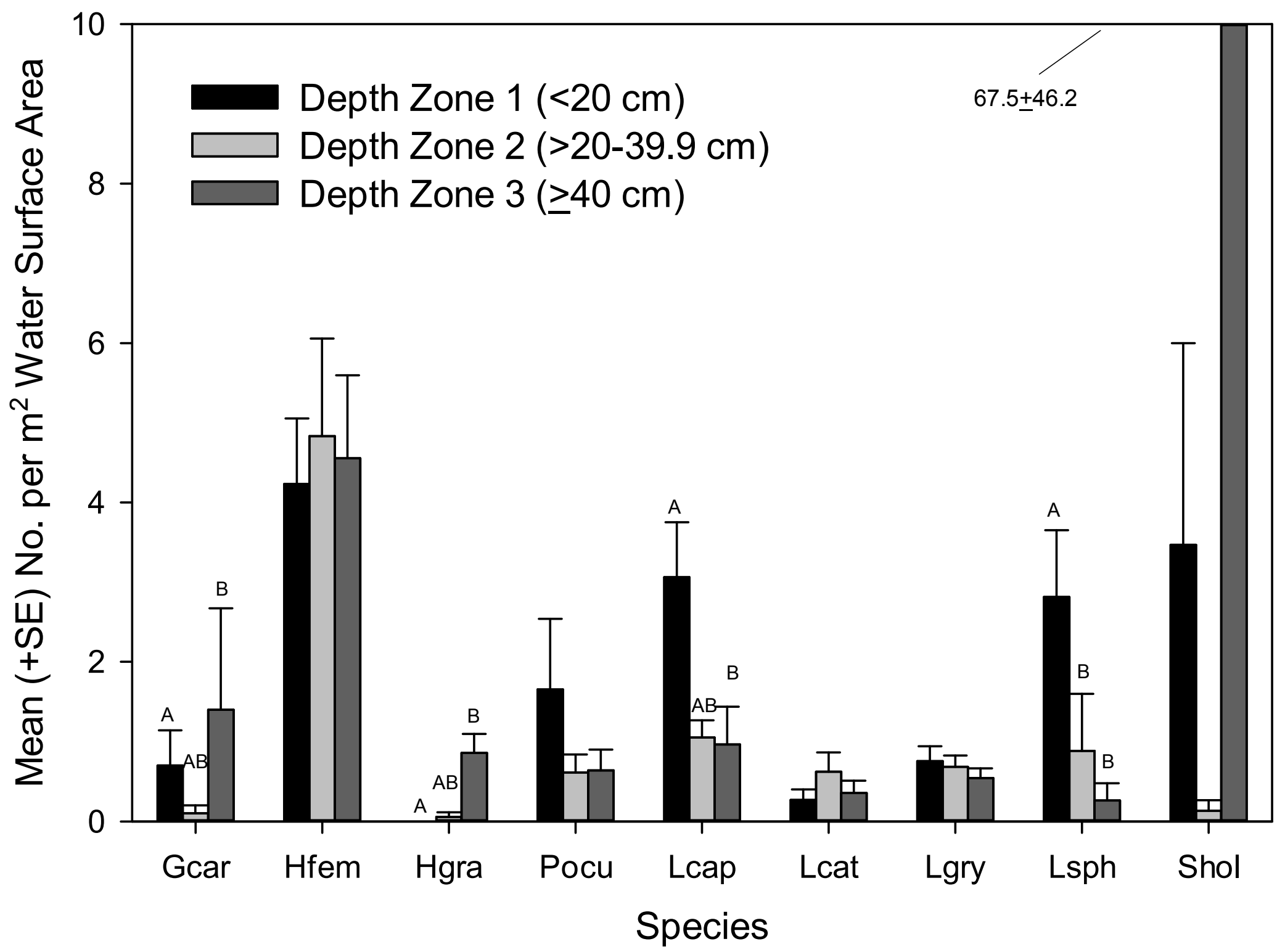



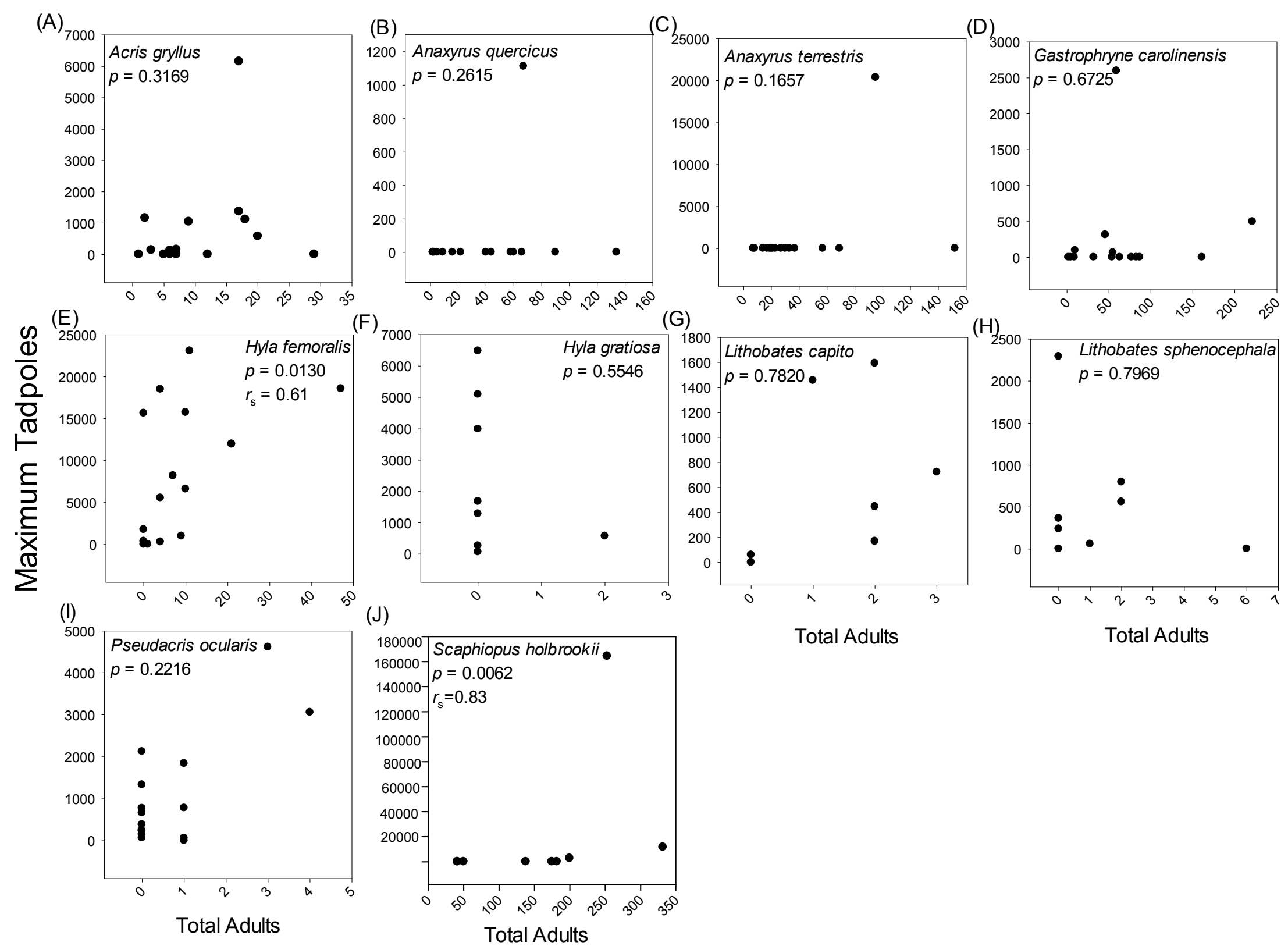

Total Adults

Total Adults 

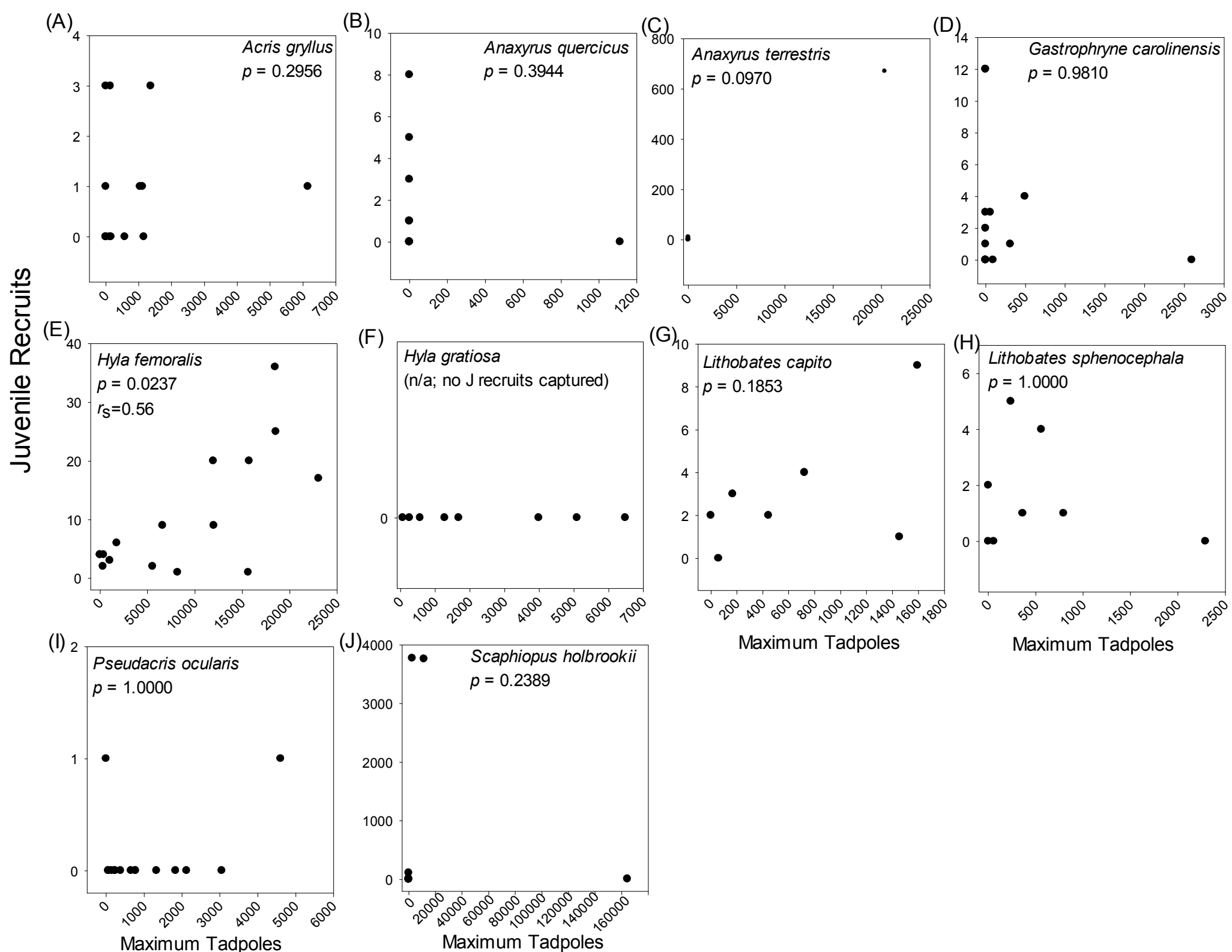

Maximum Tadpoles

Maximum Tadpoles

Maximum Tadpoles 